\title{
Effects of an Internet-based informational video on preoperative anxiety in patients with colorectal cancer
}

\author{
Myung Jo Kim¹, Heung-Kwon $\mathrm{Oh}^{2}$, Keun Chul Lee², Hyun Hui Yang'², Bon-Wook Koo³, Jebong Lee ${ }^{4}$, \\ Min-Hyun Kim${ }^{2}$, Sung II Kang ${ }^{2}$, Duck-Woo Kim², Sung-Bum Kang ${ }^{2}$ \\ ${ }^{1}$ Department of Surgery, Chungbuk National University Hospital, Cheongju, Korea \\ ${ }^{2}$ Department of Surgery, Seoul National University Bundang Hospital, Seongnam, Korea \\ ${ }^{3}$ Department of Anesthesiology and Pain Medicine, Seoul National University Bundang Hospital, Seongnam, Korea \\ ${ }^{4}$ Division of Statistics, Medical Research Collaborating Center, Seoul National University Bundang Hospital, Seongnam, Korea
}

\begin{abstract}
Purpose: Surgery is the primary curative treatment for colorectal cancer; however, it remains a frightening procedure that can cause stress and pain in affected patients. Therefore, patients typically experience significant anxiety during the preoperative period, which has been associated with poorer outcome after surgery. This study aimed to evaluate the effect of an Internet-based informational video on preoperative anxiety level in patients with colorectal cancer.

Methods: This prospective, single-arm, observational study included patients scheduled to undergo elective colorectal cancer surgery, who did not have a history of previous surgery or major cognitive impairment. The primary outcome measure was the change in Amsterdam Preoperative Anxiety and Information Scale - Anxiety (APAIS-A) before and after watching a 5-min informational video (https://youtu.be/VzhtOMPUe4Q) during the preoperative period. Secondary outcome measures were the change in Hospital Anxiety and Depression Scale (HADS), length of postoperative hospital day, and postoperative morbidity.

Results: Thirty-two patients were enrolled. Anxiety was significantly decreased after watching the video (APAIS-A score: from $10.8 \pm 3.7$ to $8.2 \pm 3.2, P<0.001$, mean reduction: $22.2 \%$ ). HADS score was also significantly decreased (from $5.8 \pm 4.4$ to $4.0 \pm 3.3, P=0.001$, mean reduction: $26.5 \%$ ). All preoperative anxiety level did not significantly differ between patients who developed postoperative complication and those who did not.

Conclusion: The informational video was an effective tool to reduce preoperative anxiety. Viewing this video may confer a higher level of confidence and realistic expectations, as well as reducing patients' preoperative anxiety.

[Ann Surg Treat Res 2019;96(6):290-295]
\end{abstract}

Key Words: Internet, Social media, Anxiety, Surgery

\section{INTRODUCTION}

Colorectal cancer (CRC) is a major cause of morbidity and mortality worldwide [1]. In Korea, it is the third most common cancer, and its incidence has gradually increased since 2010 [2]. The standard curative treatment for CRC is surgery; however it is an invasive procedure that can cause stress and pain in affected patients.

Anxiety is common in patients with CRC [3], particularly regarding what will happen during the hospitalization period and the potential complications and outcomes of surgery $[4,5]$. Some $60 \%$ to $80 \%$ of surgical patients experience preoperative
Received September 13, 2018, Revised March 11, 2019, Accepted March 28, 2019

Corresponding Author: Heung-Kwon Oh

Department of Surgery, Seoul National University Bundang Hospital, 166

Gumi-ro, Bundang-gu, Seongnam 13620, Korea

Tel: +82-31-787-7105, Fax: +82-31-787-4078

E-mail: crsohk@gmail.com

ORCID code: https://orcid.org/0000-0002-8066-2367
- The preliminary results of this study will be presented at the annual meeting of the European Society of Coloproctology, to be held from September 20-22, 2017, in Berlin, Germany.

Copyright (C) 2019, the Korean Surgical Society

(c) Annals of Surgical Treatment and Research is an Open Access Journal. All articles are distributed under the terms of the Creative Commons Attribution NonCommercial License (http://creativecommons.org/licenses/by-nc/4.0/) which permits unrestricted non-commercial use, distribution, and reproduction in any medium, provided the original work is properly cited. 
anxiety [6-8]. Increased preoperative anxiety is associated with pathophysiological responses [9], increased requirement for anesthetic drugs [10], and increased requirement for postoperative analgesia [11]. Therefore, reducing preoperative anxiety may help to improve surgical outcome [12].

The provision of preoperative information is essential to reducing patients' anxiety. The most commonly used format for preoperative information is written consent. However, not all patients have sufficient knowledge to understand this information, and their retention of the information varies [6]. In order to overcome the limitations of written information, multimedia methods such as video have been adopted more recently. Video information is advantageous in that it can provide basic information of equal quality to all patients [13]. Several randomized controlled studies demonstrated that video information decreased preoperative anxiety $[6,14,15]$ although another study did not support those effects [16].

This preliminary study aimed to investigate the effect of an Internet-based informative video on preoperative anxiety in patients with colon cancer, with the aim of providing scientific evidence to support the theoretical basis for preventing preoperative anxiety and consequently improving postoperative outcomes.

\section{METHODS}

\section{Study design}

This single-arm, prospective, pragmatic observational study included patients who were scheduled to undergo elective surgery for CRC with curative intent at a single center, between 20 to 75 years of age, and able to understand the questionnaire and provide informed consent. Patients who had a previous

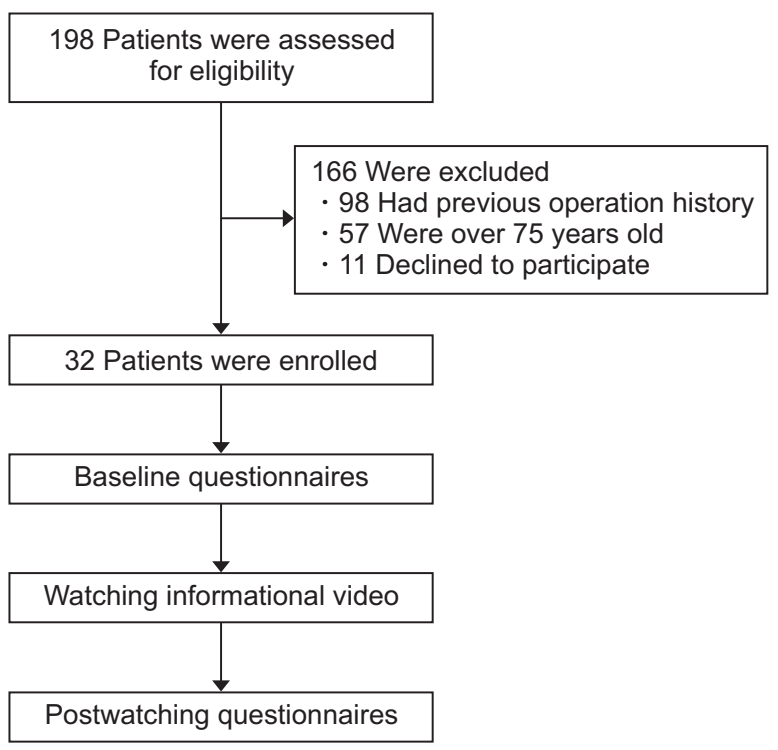

Fig. 1. Flow diagram of the study. history of surgery, major cognitive impairment or psychological disease that could influence the outcomes or who required emergent surgery were excluded (Fig. 1). All participants were educated by the study coordinator how to watch the video and complete questionnaires on the one day before surgery, after bowel preparation. Each questionnaire was collected by the study coordinator when the patient completed it before and after watching the video, and the interval was at least 2 hours. This study was approved by the Ethics Review Board at Seoul National University Bundang Hospital (approval number: B-1608-359-302) and was registered with the Clinical Trials Registry (NCT02873455).

\section{Video}

A 5-minute video in the Korean language was produced in collaboration with Talent Management Division in Seoul National University Bundang Hospital that provided various multimedia services to our institute. The video described the course of the operation day, conditions of the operating theater, operational

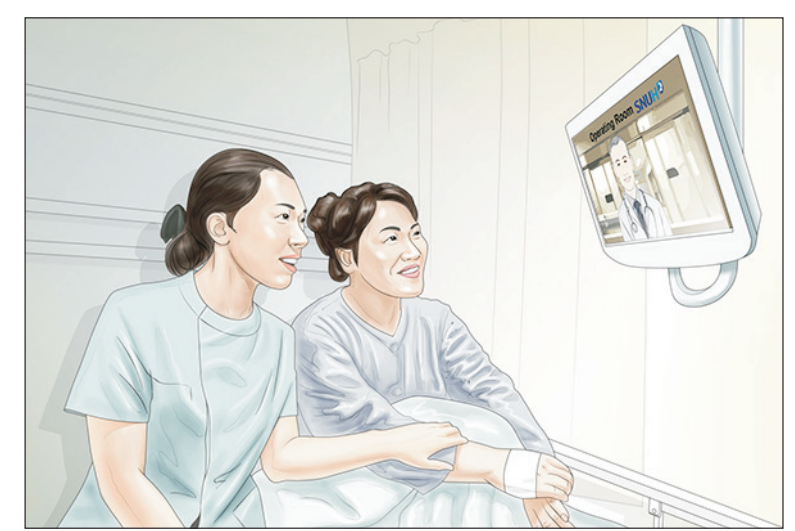

Fig. 2. The patient watches informational video about colorectal surgery using digital monitor device connected to the smart bed system.

\begin{tabular}{|c|c|c|c|c|c|}
\hline \multicolumn{6}{|l|}{ 수술전 불안 평가(APAIS) } \\
\hline \multicolumn{6}{|l|}{ 다음 물음에 본인이 느끼는 정도에 따라 표시해 주세요. } \\
\hline \multicolumn{6}{|c|}{ (1) 매우 그렇지 않다 (2) 그렇지 않다 (3) 보통이다 (4)그렇다 (5) 매우 그렇다 } \\
\hline \multicolumn{6}{|l|}{ 마취와 관련하여 } \\
\hline 1. 마취가 걱정이 된다. & (1) & (2) & (3) & (4) & (5) \\
\hline 2. 마취에 대한 생각이 머리에서 떠나지 않는다. & (1) & (2) & (3) & (4) & (5) \\
\hline 3. 마취에 대한 정보를 알고 싶다. & (1) & (2) & (3) & (4) & (5) \\
\hline \multicolumn{6}{|l|}{ 수술과 관련하여 } \\
\hline 1. 수술이 걱정이 된다. & (1) & (2) & (3) & (4) & (5) \\
\hline 2. 수술에 대한 생각이 머리에서 떠나지 않는다. & (1) & (2) & (3) & (4) & (5) \\
\hline 3. 수술에 대한 정보를 알고 싶다. & (1) & (2) & (3) & (4) & (5) \\
\hline
\end{tabular}

Fig. 3. Amsterdam Preoperative Anxiety and Information Scale questionnaire, translated into Korean. 
procedure, and encouraging messages from the anesthesiologist and attending surgeons. In this video, 3 attending surgeons appear and explain to each other in a lighthearted and friendlyalthough technically correct-manner what an operation room is like, and the various objects and procedures involved. The video was watched using a variety of tools: digital monitor device connected to the smart bed system in our hospital (Fig. 2) [17], any device with internet access to enter the URL address of the video (https://youtu.be/VzhtOMPUe4Q) directly, or mobile device with $\mathrm{QR}$ code scanning.

\section{Questionnaire}

Two questionnaires that have been translated and validated in Korean were used to evaluate preoperative anxiety level: the Amsterdam Preoperative Anxiety and Information Scale (APAIS) and the Hospital Anxiety and Depression Scale (HADS) [18].

The APAIS is a self-reporting questionnaire consisting of 6 items (Fig. 3). Two items are dedicated to the assessment of anesthesia-related anxiety, 2 items assess surgery-related anxiety, and 2 items evaluate the desire for information. Thus, the APAIS assesses anxiety about anesthesia, anxiety about

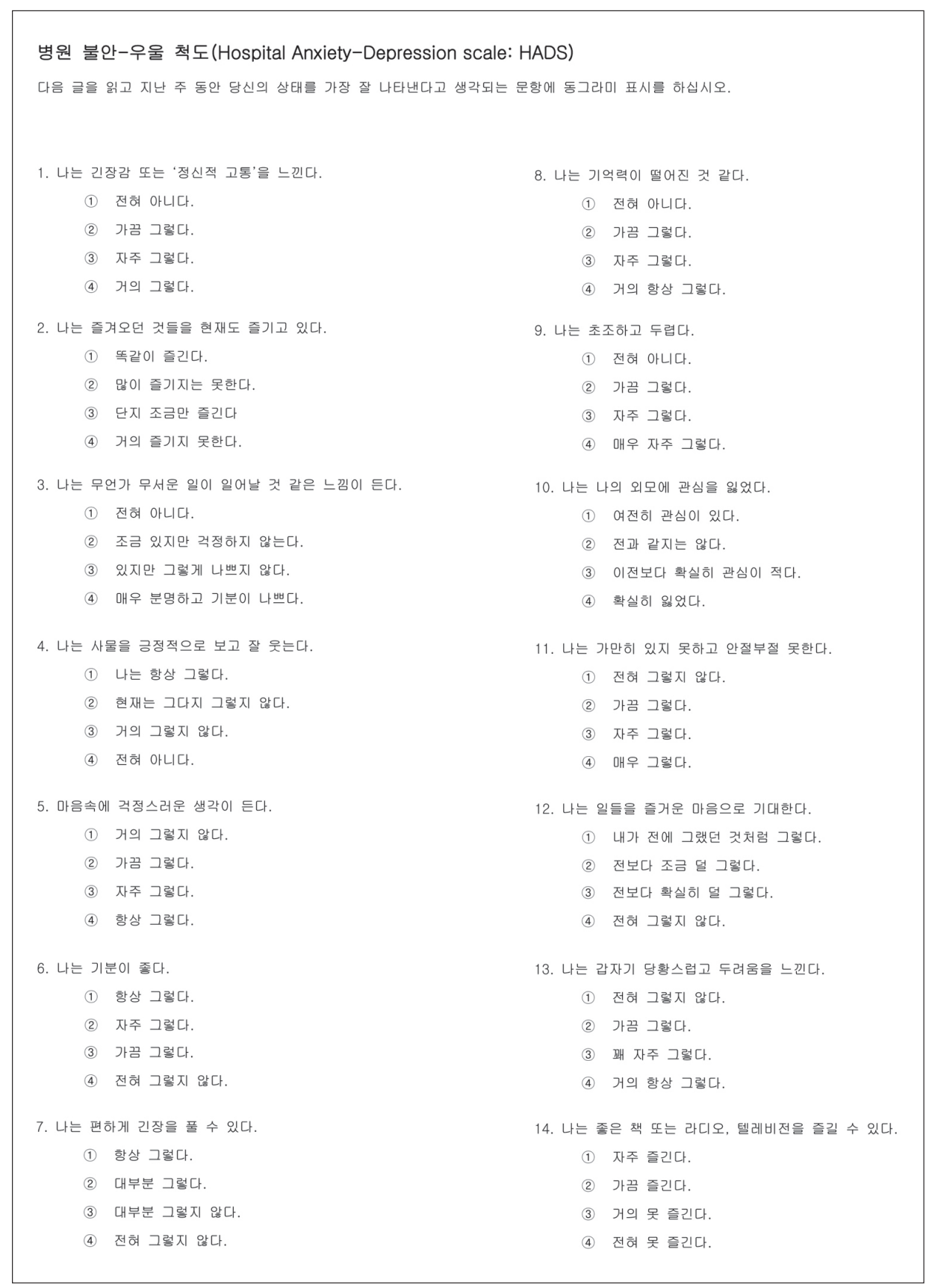

Fig. 4. Hospital Anxiety and Depression Scale questionnaire, translated into Korean. 
surgery (with the sum of both serving as the global anxiety index), and the desire for information. We divided these items into 2 groups, all anxiety items for APAIS - Anxiety (APAIS-A) and all information items for APAIS - Information. The items were answered using a 5-point Likert scale ranging from 1 ("not at all") to 5 ("extremely") [19].

The HADS is designed specifically to detect symptoms of anxiety and depression in medically compromised patients. This is divided into 2 sections: anxiety and depression. Each section has 7 items and the answer was graded from 0 to 3 (Fig. 4) [20].

Primary outcome was the difference in APAIS-A, which was more useful method to evaluate the preoperative anxiety [18]. Secondary outcome was the difference in HADS, length of postoperative hospital day, and postoperative morbidity.

\section{Sample size and statistical analysis}

Before starting this study, a pilot study was performed on 10 patients. Based on APAIS-A score, the mean preoperative anxiety level was 10.8 . A power analysis assuming a $20 \%$ decrease of anxiety level and 5\% drop-out rate, with a power of $90 \%$ at a $5 \%$ level of significance using 2 -sided paired t-test, a mean of paired differences of 2.2, and an estimated standard deviation (SD) of differences of 3.5 indicated that a total sample size of 32 patients would be sufficient. Data were analyzed using STATA 14 (StataCorp LP, College Station, TX, USA) and IBM SPSS Statistics ver. 22.0 (IBM Co., Armonk, NY, USA). Continuous variables were reported as means (SD), and the

Table 1. Patients' demographic characteristics

\begin{tabular}{cc}
\hline \multicolumn{1}{c}{ Variable } & Patients $(\mathrm{n}=32)$ \\
Age $(\mathrm{yr})$ & $57.9 \pm 10.3$ \\
$\leq 60$ & 17 \\
$>60$ & 15 \\
Sex & $24(75.0)$ \\
Male & $8(25.0)$ \\
Female & $2(6.3)$ \\
Education & $5(15.6)$ \\
Elementary & $13(40.6)$ \\
Middle school & $12(37.5)$ \\
High school & \\
University & $13(40.6)$ \\
ASA PS classification & $19(59.4)$ \\
I & \\
II & $20(62.5)$ \\
Surgeon & $9(28.1)$ \\
1 & $3(9.4)$ \\
2 &
\end{tabular}

Values are presented as mean \pm standard deviation or number $(\%)$. ASA PS, American Society of Anesthesiologists physical status.

${ }^{a)} A$ total of 3 surgeons participated in the surgery and were represented only by numbers. paired t-test was used to assess the difference in anxiety level before and after watching the video. The Wilcoxon signed-rank test for paired abnormally distributed data was used to assess statistical significance between groups. A P-value less than 0.05 was considered statistically significant.

\section{RESULTS}

We calculated the APAIS-A score as the sum of 2 categories concerning anxiety about surgery and anesthesia. The demographic characteristics of enrolled patients are shown in Table 1. Thirty-two patients were included. Their mean age was $57.9 \pm 10.3$ years, $75 \%$ were men, and $78 \%$ had more than a high school education.

Patients' initial preoperative anxiety score was $10.8 \pm 3.8$, which was reduced significantly after watching the video $(2.6 \pm 2.6,22.2 \% ; \mathrm{P}<0.001)$. The APAIS score for desire for

Table 2. Mean scores of anxiety scales in each group, with the difference between before and after watching the video

\begin{tabular}{lrrrc}
\multicolumn{1}{c}{ Group } & $\begin{array}{c}\text { Video } \\
\text { (before) }\end{array}$ & Video (after) & Difference $^{\mathrm{a})}$ & P-value \\
\hline APAIS-A & $10.8 \pm 3.8$ & $8.2 \pm 3.2$ & $2.6 \pm 2.6$ & $<0.001$ \\
APAIS-I & $6.4 \pm 2.0$ & $5.1 \pm 1.9$ & $1.3 \pm 1.8$ & $<0.001$ \\
HADS-A & $5.8 \pm 4.4$ & $4.0 \pm 3.3$ & $1.8 \pm 2.8$ & 0.001 \\
HADS-D & $6.4 \pm 3.9$ & $5.2 \pm 3.9$ & $1.2 \pm 2.5$ & 0.01 \\
\hline
\end{tabular}

Values are presented as mean \pm standard deviation.

APAIS-A, Amsterdam Preoperative Anxiety and Information Scale - Anxiety; APAIS-I, Amsterdam Preoperative Anxiety and Information Scale - Information; HADS-A, Hospital Anxiety and Depression Scale - Anxiety; HADS-D, Hospital Anxiety and Depression Scale - Depression.

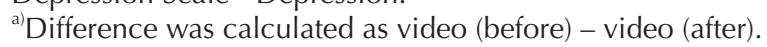

Table 3. Comparison of preoperative anxiety scales according to the postoperative complication

\begin{tabular}{lcc}
\hline \multicolumn{1}{c}{ Variable } & $\begin{array}{c}\text { No complication } \\
(\mathrm{n}=27)\end{array}$ & $\begin{array}{c}\text { Complication } \\
(\mathrm{n}=5)\end{array}$ \\
\hline APAIS-A (before) & $10.7 \pm 3.5$ & $11.0 \pm 5.7$ \\
APAIS-I (before) & $6.4 \pm 2.0$ & $6.2 \pm 2.4$ \\
HADS-A (before) & $5.6 \pm 4.1$ & $6.8 \pm 6.1$ \\
HADS-D (before) & $6.2 \pm 4.1$ & $7.4 \pm 2.1$ \\
APAIS-A (after) & $8.2 \pm 3.2$ & $8.4 \pm 3.6$ \\
APAIS-I (after) & $5.2 \pm 2.1$ & $4.8 \pm 0.8$ \\
HADS-A (after) & $4.1 \pm 3.5$ & $3.6 \pm 1.8$ \\
HADS-D (after) & $5.0 \pm 4.0$ & $6.0 \pm 3.7$ \\
\hline
\end{tabular}

Values are presented as mean \pm standard deviation.

APAIS-A, Amsterdam Preoperative Anxiety and Information Scale - Anxiety; APAIS-I, Amsterdam Preoperative Anxiety and Information Scale - Information; HADS-A, Hospital Anxiety and Depression Scale - Anxiety; HADS-D, Hospital Anxiety and Depression Scale - Depression. 
information and the HADS score were also significantly reduced after patients watched the video (both $\mathrm{P}<0.001$ ) (Table 2). There were 2 patients who demonstrated an increased anxiety score. The postoperative complication rate was $15 \%$ (5 of 32). Three patients had a prolonged ileus for more than 5 days after surgery, one patient had voiding difficulty, and one had diarrhea. All preoperative anxiety level also did not significantly differ between patients who developed postoperative complications and those who did not $(\mathrm{P}>0.05)$ (Table 3).

\section{DISCUSSION}

Many patients who have no experience of surgery report preoperative anxiety and this anxiety can affect a patient's outcome after surgery. Most information aimed at reducing preoperative anxiety is given to the patient verbally or in writing, but it is not always easy for the patient to understand. Recent research has demonstrated that even when giving information to healthy, educated young volunteers in an ideal environment, their recall is low [21]. To overcome these limitations, previous studies have attempted to reduce patient anxiety using a variety of information tools with mixed results [14]. The most effective means of reducing preoperative anxiety is to provide patients with hospital experience.

Video is one of the best tools for providing information. Patients can understand medical information with easyto-comprehend terms and visual descriptions. In addition, if produced by the medical institution itself, video can be expected to provide accurate and appropriate information to the patient. For example, while children may have greater difficulty understanding routine or medical terms than adults, a recent report found that watching a video or 2-dimensional animation before surgery could reduce their anxiety [22]. In the present study, video was also found to effectively reduce preoperative anxiety in patients with no surgical experience.

The Internet is widely used to disseminate health information. About $70 \%$ of people in their fifties and over are comfortable using the Internet, and even over the age of $65,41 \%$ of people use the Internet to find health information. However, the quality of information on the Internet is not always guaranteed. The fact that content has been accessed by many viewers does not indicate the quality of its information, which is often poor [23]. Nevertheless, the Internet has the advantage of being easily accessible; therefore, combining it with other media can have a synergistic positive effect. In terms of ease of use, feasibility, and availability of information, Internet-based multimedia leads to higher patient satisfaction [24].

Patient outcome can be difficult to measure. Previous studies have shown mixed results for postoperative outcomes. In orthopedic surgery, improved preoperative anxiety led to better postoperative recovery, higher patient satisfaction, and reduced pain level [14]. However in children, there were no differences in postoperative behavioral change [25]. In our study, 5 patients had postoperative complications, and there was no significant difference in all preoperative anxiety score between patients who did and did not experience complications.

This study showed that watching preoperative explaining video clip improves comfort to the patient entirely without the costly intervention of drug or test in clinical aspects. However, there have been several limitations in this study. The sample size was too small to demonstrate the efficacy of this video. There was also a selection bias, because only patients who had not undergone surgery were included. Despite the positive results, it is difficult to expect reliability because the study was designed with a single arm. Studies involving larger sample sizes, such as randomized controlled trials, as well as those including patients who have experienced other types of surgery, are needed to confirm and extend the present results.

In conclusion, the informational Internet-based video evaluated in the present study was an effective tool to reduce preoperative anxiety. This video can provide realistic experience and accurate information to patients with CRC and is easily accessible to patients. Further evaluation will be needed, including patients who have experienced different types of surgery in this setting.

\section{CONFLICTS OF INTEREST}

No potential conflict of interest relevant to this article was reported.

\section{ACKNOWLEDGEMENTS}

The authors thank Junghun Lee, Eun-Sun Lee, Hyeon Ji Kim, Hee Ra Jin, Hyo Jeong Lee, Jeong Won So, Da Rong Lee, and Suna Kim for their assistance and advice.

\section{REFERENCES}

1. Siegel R, Naishadham D, Jemal A. Cancer statistics, 2012. CA Cancer J Clin 2012;62:
10-29.

2. Shin A, Kim KZ, Jung KW, Park S, Won YJ,
Kim J, et al. Increasing trend of colorectal cancer incidence in Korea, 1999-2009. 
Cancer Res Treat 2012;44:219-26.

3. Tsunoda A, Nakao K, Hiratsuka K, Yasuda N, Shibusawa M, Kusano M. Anxiety, depression and quality of life in colorectal cancer patients. Int J Clin Oncol 2005;10: 411-7.

4. Grieve RJ. Day surgery preoperative anxiety reduction and coping strategies. $\mathrm{Br} \mathrm{J}$ Nurs 2002;11:670-8.

5. Pritchard MJ. Identifying and assessing anxiety in pre-operative patients. Nurs Stand 2009:23:35-40.

6. Jlala HA, French JL, Foxall GL, Hardman JG, Bedforth NM. Effect of preoperative multimedia information on perioperative anxiety in patients undergoing procedures under regional anaesthesia. $\mathrm{Br} \mathrm{J}$ Anaesth 2010;104:369-74.

7. Norris W, Baird WL. Pre-operative anxiety: a study of the incidence and aetiology. $\mathrm{Br}$ J Anaesth 1967;39:503-9.

8. Shevde K, Panagopoulos G. A survey of 800 patients' knowledge, attitudes, and concerns regarding anesthesia. Anesth Analg 1991;73:190-8.

9. Williams JG, Jones JR. Psychophysiological responses to anesthesia and operation. JAMA 1968;203:415-7.

10. Goldmann L, Ogg TW, Levey AB. Hypnosis and daycase anaesthesia. A study to reduce pre-operative anxiety and intraoperative anaesthetic requirements. Anaesthesia 1988:43:466-9.

11. Ip HY, Abrishami A, Peng PW, Wong J, Chung F. Predictors of postoperative pain and analgesic consumption: a qualitative systematic review. Anesthesiology 2009; 111:657-77.
12. Lee A, Chui PT, Gin T. Educating patients about anesthesia: a systematic review of randomized controlled trials of mediabased interventions. Anesth Analg 2003; 96:1424-31.

13. Pearson S, Maddern GJ, Hewett P. Interacting effects of preoperative information and patient choice in adaptation to colonoscopy. Dis Colon Rectum 2005;48: 2047-54.

14. O'Connor MI, Brennan K, Kazmerchak S, Pratt J. YouTube videos to create a "virtual hospital experience" for hip and knee replacement patients to decrease preoperative anxiety: a randomized trial. Interact J Med Res 2016;5:e10.

15. Tou S, Tou W, Mah D, Karatassas A, Hewett P. Effect of preoperative twodimensional animation information on perioperative anxiety and knowledge retention in patients undergoing bowel surgery: a randomized pilot study. Colorectal Dis 2013;15:e256-65.

16. Salzwedel C, Petersen C, Blanc I, Koch $\mathrm{U}$, Goetz AE, Schuster M. The effect of detailed, video-assisted anesthesia risk education on patient anxiety and the duration of the preanesthetic interview: a randomized controlled trial. Anesth Analg 2008;106:202-9.

17. Yoo S, Lee KH, Baek H, Ryu B, Chung E, Kim K, et al. Development and user research of a smart bedside station system toward patient-centered healthcare system. J Med Syst 2015:39:86.

18. Shin WJ, Kim YC, Yeom JH, Cho SY, Lee DH, Kim DW. The validity of Amsterdam Preoperative Anxiety Information Scale in the assessment of the preoperative anxiety - compared with hospital anxiety depression scale and visual analogue scale. Korean J Anesthesiol 1999:37:17987.

19. Moerman N, van Dam FS, Muller MJ, Oosting H. The Amsterdam Preoperative Anxiety and Information Scale (APAIS). Anesth Analg 1996;82:445-51.

20. Zigmond AS, Snaith RP. The hospital anxiety and depression scale. Acta Psychiatr Scand 1983;67:361-70.

21. Sandberg EH, Sharma R, Sandberg WS. Deficits in retention for verbally presented medical information. Anesthesiology 2012;117:772-9.

22. Batuman A, Gulec E, Turktan M, Gunes Y, Ozcengiz D. Preoperative informational video reduces preoperative anxiety and postoperative negative behavioral changes in children. Minerva Anestesiol 2016;82: 534-42.

23. Chow CH, Van Lieshout RJ, Schmidt LA, Dobson KG, Buckley N. Systematic review: audiovisual interventions for reducing preoperative anxiety in children undergoing elective surgery. J Pediatr Psychol 2016;41:182-203.

24. Nehme J, El-Khani U, Chow A, Hakky S, Ahmed AR, Purkayastha S. The use of multimedia consent programs for surgical procedures: a systematic review. Surg Innov 2013;20:13-23.

25. Desai T, Shariff A, Dhingra V, Minhas D, Eure M, Kats M. Is content really king? An objective analysis of the public's response to medical videos on YouTube. PLoS One 2013;8:e82469. 